\title{
Globe
}

Revue internationale d'études québécoises

\section{Michèle Dagenais, Montréal et l'eau : une histoire environnementale, Montréal, Boréal, 2011}

\section{François Walter}

Volume 15, numéro 1-2, 2012

URI : https://id.erudit.org/iderudit/1014638ar

DOI : https://doi.org/10.7202/1014638ar

Aller au sommaire du numéro

\section{Éditeur(s)}

Globe, Revue internationale d'études québécoises

\section{ISSN}

1481-5869 (imprimé)

1923-8231 (numérique)

Découvrir la revue

Citer ce compte rendu

Walter, F. (2012). Compte rendu de [Michèle Dagenais, Montréal et l'eau : une histoire environnementale, Montréal, Boréal, 2011]. Globe, 15(1-2), 337-339.

https://doi.org/10.7202/1014638ar d'utilisation que vous pouvez consulter en ligne.

https://apropos.erudit.org/fr/usagers/politique-dutilisation/ 


\title{
RECENSIONS
}

\author{
Maxime Raymond-Dufour (éd.)
}

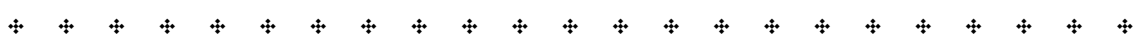

\section{Michèle Dagenais \\ Montréal et l'eau: une histoire environnementale, Montréal, Boréal, 2011.}

Spécialiste de l'histoire urbaine, l'auteure a su croiser les dimensions temporelles et spatiales pour nous donner un bel exemple des possibilités que donnent à la recherche les problématiques de l'histoire environnementale dont elle se réclame. En effet, le fleuve aurait pu être étudié en lui-même, tout comme la ville d'ailleurs, en insistant éventuellement sur les problèmes que posent l'approvisionnement en eau et la gestion des flux. L'intérêt d'aborder de front les deux entrées d'habitude séparées - la ville d'un côté, le fleuve de l'autre - est de faire comprendre les relations constitutives du milieu urbain au travers d'enjeux pluriels. À condition de la dénaturaliser et de l'historiciser, l'eau devient un objet historique. Tantôt menace, tantôt ressource, tantôt les deux à la fois, sa place dans l'histoire n'est jamais acquise puisque les contextes s'avèrent mouvants. En un mot, ce livre décrit les usages sociaux de l'eau dans un environnement urbain lui-même en pleine évolution, celui de la métropolisation de Montréal.

Le projet innove par rapport à l'historiographie existante qui s'est surtout satisfaite d'observer la marginalisation de l'eau dans le tissu urbain pour se concentrer sur l'importance fonctionnelle de la façade fluviale. Durant les années 1930, le grand géographe Raoul Blanchard s'est par exemple intéressé à cette sorte de "Mésopotamie complexe» que façonnent les chenaux des différents cours d'eau du bassin du Saint-Laurent entrelaçant les terres montréalaises. Ensuite, on a l'impression d'une mise de côté du thème, puisque l'ouverture du canal qui facilite la navigation vers les Grands Lacs 
annihile les ruptures de charge attribuables aux rapides du fleuve. Or ce trait géographique contraignant avait permis le développement de la ville. Par le parachèvement, en 1959, du nouveau canal de la Rive-Sud, long de 29 kilomètres, la ville perd son statut de port océanique intérieur le plus avancé. Les contraintes fluviales ont été en quelque sorte gommées, mais d'autres usages vont s'imposer. C'est ce qui guide l'analyse de Michèle Dagenais.

La démonstration est construite de manière chronologique à travers plusieurs séquences fortes. La première évoque le fonctionnement de la ville ancienne et les changements majeurs apportés par le démantèlement des fortifications en 1801. En même temps, les autorités fixent un plan pour anticiper le développement du tissu urbain. Tout le XIXe siècle apparaît donc comme un temps de redéfinition de Montréal afin d'inscrire la ville dans le territoire autrement que par de simples limites physiques. Avec ses flux contrôlés et canalisés, Montréal prend l'allure d'une "ville d'eaux", contrainte par la multitude de rivières et de fossés qu'enjambent une soixantaine de ponts. Le rôle du Saint-Laurent se renforce alors que Montréal devient une grande ville industrielle. Son aménagement devient une priorité (approfondissement, constructions des quais, d'un pont, captage de l'eau). On s'efforce aussi de discipliner les rapides de Lachine, travaux entrepris durant les années 1820 avec la construction d'un premier canal. À l'intérieur de la ville, des efforts considérables visent à neutraliser les miasmes des eaux stagnantes. La solution retenue est d'accélérer la circulation des eaux. L'eau courante appartient à ce que Michel Foucault a appelé les technologies de pouvoir. Nettoyer, laver et éliminer, voilà qui implique des réseaux complexes d'adduction et d'évacuation. C'est l'occasion pour les autorités municipales de renforcer leur emprise en assurant la responsabilité de l'approvisionnement.

Outre le fleuve, d'autres cours d'eau prennent une importance nouvelle durant la phase d'industrialisation de la région. C'est le cas de la rivière des Prairies qui est très convoitée par les compagnies d'électricité. Un premier barrage est érigé à la fin des années 1920, ce qui modifie considérablement le milieu naturel tout en posant des problèmes aux municipalités riveraines qui comptaient sur sa fonction d'évacuation des eaux usées. L'auteure analyse opportunément ce dossier en introduisant des réflexions sur le thème de la justice environnementale. C'est que face aux enjeux environnementaux, les populations présentent des degrés divers de vulnérabilité et doivent apprendre à compter avec de puissants lobbies étatiques et économiques. Dans le cas concret d'un Montréal en plein développement industriel, les communautés riveraines ont l'impression d'être dépossédées de leur usage de l'eau. C'est ainsi que la baignade est interdite en 1937 à cause de l'extrême 
pollution dont on ne veut percevoir encore que les manifestations organiques. Ces «injustices" environnementales sont en partie corrigées par les équipements en centrales d'épuration (à partir de 1961). Par ailleurs, les effets du réaménagement de la navigation fluviale entraînent la migration du port : les nouvelles installations sont clôturées, ce qui prive les populations de l'accès à l'eau.

La dernière période est rythmée par une sorte de reconquête symbolique de l'eau par les habitants. Elle accompagne l'urbanisation galopante et l'aménagement d'infrastructures lourdes (routes et multiplication des ponts). Elle passe par les revendications nouvelles qui se manifestent dès les années 1970 pour valoriser la vie au grand air et l'accès à la nature dite «sauvage ». Au lieu de penser exclusivement en termes de ressources à exploiter, on en vient à considérer la valeur intrinsèque de l'eau et du milieu végétal. C'est pourquoi l'opinion n'accepte plus le simple constat que son fleuve est, comme l'écrit un journal en 1975, "malade», mais elle exige des mesures pour le guérir. C'est le contexte dans lequel s'est développée une approche plus globale de ce qu'il convient d'appeler "l'archipel de Montréal" (nom d'un vaste projet intégré qui a capoté au début des années 1980). Cette volonté de réappropriation du Saint-Laurent par les habitants se concrétise de manière spectaculaire par le développement des activités récréatives. Plonger dans le fleuve devient même une sorte d'acte de civisme militant. Par contre, les mouvements sociaux récents doivent aussi être recontextualisés. C'est ce que réussit fort bien l'auteur en conclusion en montrant comment les représentations participent de la construction d'un mythe. De fait, la population n'a pas plus vécu autrefois en symbiose avec l'eau qu'elle n'en a été totalement séparée. Michèle Dagenais conclut : «Ce qui a changé au fil du temps, ce sont les formes qu'a prises la présence de l'eau dans le paysage montréalais, et les relations entre la ville et l'eau ». Cet ouvrage le démontre parfaitement.

François Walter Université de Genève 